\title{
Antropologia Urbana: \\ da metrópole à aldeia ${ }^{1}$
}

\author{
José Guilherme Cantor Magnani² \\ Universidade de São Paulo
}

Resumo: No dia 25 de abril de 2018, o Programa de Pós-Graduação em Antropologia Social da UFMT teve como aula inaugural a Conferência "Antropologia Urbana: da metrópole à aldeia”, proferida pelo professor José Guilherme Cantor Magnani, cujas reflexões ocupam agora as páginas da Aceno. Um dos principais expoentes da Antropologia Urbana brasileira, Magnani apresenta nesta conferência a possibilidade de colocar a Antropologia Urbana em diálogo com outros campos de pesquisa, de forma a superar a antinomia "na e da cidade". Partindo de pesquisas realizadas por ele e seus orientandos, nos últimos anos, no Núcleo de Antropologia Urbana (NAU/USP), a ideia de Magnani é a de ampliar o campo da Antropologia Urbana, em diálogo com outras áreas do conhecimento.

Palavras-chave: Antropologia Urbana; Teoria Antropológica; Cidade; Metodologia.

\footnotetext{
${ }^{1}$ Transcrição de áudio: Letícia Corrêa Gonçalves, mestranda do PPGAS/UFMT. Revisão e edição: Marcos Aurélio da Silva (PPGAS/UFMT). Revisão final: Ivo Cantor Magnani.

${ }^{2}$ José Guilherme Cantor Magnani é professor titular do Departamento de Antropologia da FFLCH da USP, pesquisador nível 1-B (CNPq). É mestre em Sociologia pela Facultad Latinoamericana de Ciencias Sociales (FLACSO/CHILE). Concluiu o doutorado em Ciências Humanas (Antropologia Social) pela Universidade de São Paulo, em 1982. Defendeu tese de Livre-Docência em 2010 e de Titular em 2012 também na USP. Além de mais de 50 artigos em periódicos especializados e nove livros publicados, orientou 34 dissertações de mestrado e 17 teses de doutorado, além de ter orientado 66 trabalhos de iniciação científica na área de Antropologia. Recebeu o prêmio "Erico Vanucci Mendes CNPq/SBPC", em 1989, e o "Mérito de Humanidades", em comemoração aos 80 anos do Setor de Ciências Humanas (SCH) da UFPR, em 2018. É co-coordenador do Laboratório do Núcleo de Antropologia Urbana da USP, editor da coleção "Antropologia Hoje", editora Terceiro Nome.
} 


\title{
Urban Anthropology: from the metropolis to the village
}

\begin{abstract}
On April 25, 2018, the UFMT Postgraduate Program in Social Anthropology had, as its inaugural class, the conference "Urban Anthropology: from the metropolis to the village", given by professor José Guilherme Cantor Magnani, whose reflections now occupied as pages of Aceno. One of the main exponents of Brazilian Urban Anthropology, Magnani presents at this conference the possibility of placing an urban anthropology in dialogue with other fields of research, in order to overcome an antinomy "in and of the city". Based on research carried out by him and his students, in the last years, at the Research Center of Urban Anthropology (NAU/USP), Magnani's idea is to open the field of Urban Anthropology a little more to see where it is most effective, including in other areas of knowledge.
\end{abstract}

Keywords: Urban Anthropology; Anthropological Theory; City; Methodology.

\section{Antropología Urbana: de la metrópoli a la aldea}

\begin{abstract}
Resumen: El 25 de abril de 2018, el Programa de Posgrado en Antropología Social de la UFMT tuvo como su clase inaugural la conferencia "Antropológica Urbana: de la metrópoli a la aldea”, impartida por el profesor José Guilherme Cantor Magnani, reflexiones ahora ocupadas como páginas de Aceno. Magnani, uno de los principales exponentes de la antropología urbana brasileña, presenta en esta conferencia la posibilidad de colocar una antropología urbana en diálogo con otros campos de investigación, para superar una antinomia "en y de la ciudad". Según la investigación realizada por él y sus estudiantes, en los últimos años, en el Núcleo de Antropología Urbana (NAU/USP), la idea de Magnani es abrir un poco más el campo de la Antropología Urbana en diálogo con otras áreas de conocimiento.
\end{abstract}

Palabras clave: Antropología urbana; Teoría antropológica; Ciudad; Metodología. 


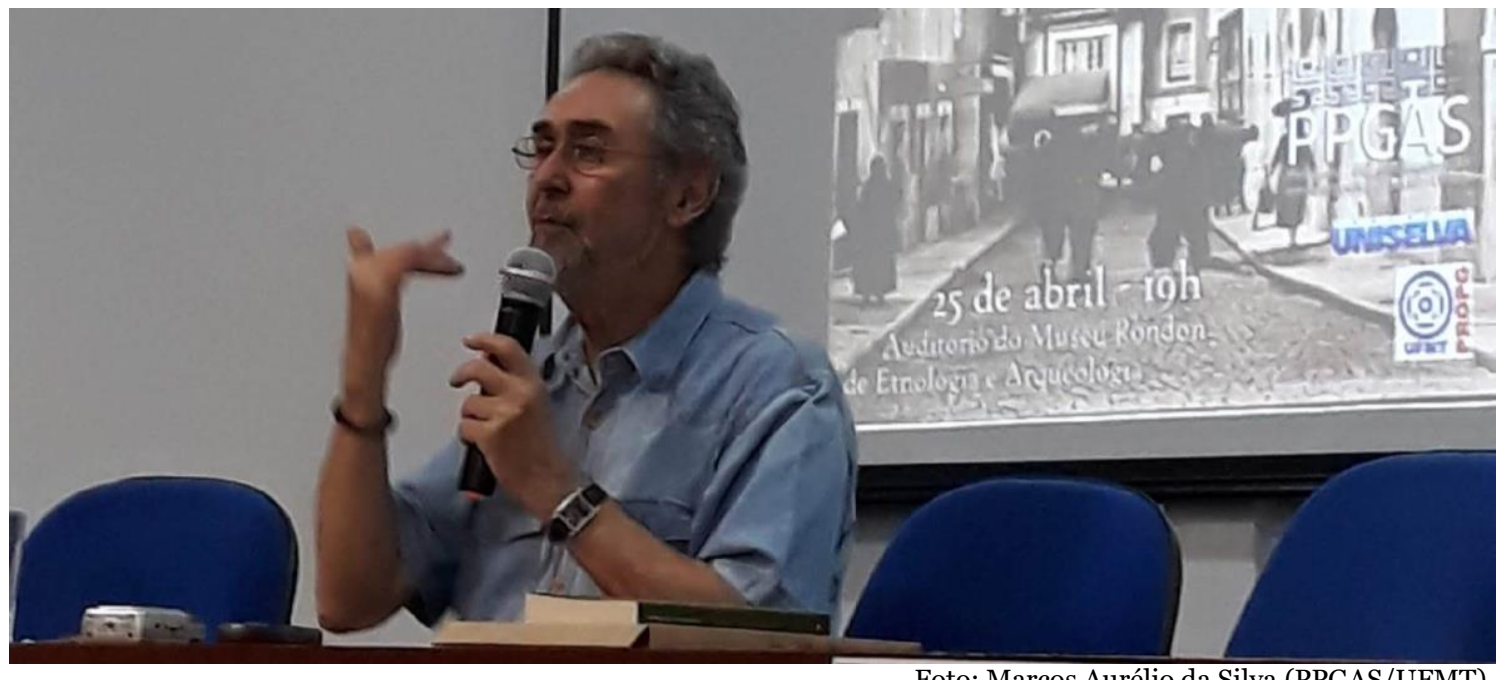

Foto: Marcos Aurélio da Silva (PPGAS/UFMT)

$\mathrm{F}$ lico muito honrado em haver sido convidado para essa aula inaugural que também é, para mim, uma oportunidade de ter contato e conhecer as linhas de pesquisa de vocês e saber como a Antropologia Urbana vem sendo pensada por aqui. Conversando com os professores, sei que vocês já leram algumas obras minhas, então corro talvez o risco de repetir um ou outro conceito. Terei, contudo, de me referir a elas para construir um argumento e atender ao título "Da Metrópole à Aldeia", o que significa abrir um pouco o campo da Antropologia Urbana para ver onde ela é mais eficaz, inclusive em outras áreas do conhecimento. Farei uma reconstituição do campo da antropologia, principalmente em São Paulo, onde ela se estabelece a partir dos anos 1930, e depois quando se consolida, com o trabalho de duas professoras muito importantes para minha formação, Ruth Cardoso e Eunice Durham: ambas iniciam uma linha de pesquisa inovadora da antropologia em discussão com a sociologia da época. A partir daí seus orientandos se espalham por várias universidades do país abrindo novos campos de pesquisa.

Há uma linha específica com a qual trabalho, na perspectiva do lazer e sociabilidade na periferia de São Paulo - um dos últimos livros que lancei se chama Da periferia ao centro: trajetórias de pesquisa em Antropologia Urbana (MAGNANI, 2012). No centro dessa metrópole, a partir do trabalho de campo aí realizado, surgiram novas categorias analíticas, além das já elaboradas na pesquisa em regiões periféricas: algumas já são conhecidas por vocês e continuamente colocadas à prova por meus alunos em suas pesquisas. Não são categorias fixas e estão sempre em diálogo com o campo. Tentarei mostrar como essas categorias, elaboradas no imenso laboratório que é a cidade de São Paulo, se estendem para outras escalas urbanas, seja em cidades médias ou em contextos como o da a Amazônia, onde foi possível trabalhar com os chamados "índios urbanos", ou seja, a presença de populações indígenas em cidades. Há então uma progressão na linha da Antropologia Urbana, que se forma numa determinada perspectiva, mas que pode se abrir e continua se abrindo.

\section{A Escola de Chicago}

Quando se fala de Antropologia Urbana para um público não especializado - não é o caso aqui - a ideia que se faz é de um ramo tardio da antropologia clássica realizada com populações de pequena escala - indígenas, comunidades 
rurais, grupos isolados -, que só muito tempo depois teria surgido. Mas quando se faz uma análise mais histórica, percebem-se diálogos muito interessantes. Por exemplo, um livro clássico para nós, Os Argonautas do Pacífico Ocidental (MALINOWSKI, 1978), foi publicado originalmente em 1922. Mas em 1925, Robert Ezra Park, da Escola de Chicago, tem um texto que nos dá uma perspectiva de estudos urbanos na Antropologia:

\begin{abstract}
Nos dias de hoje, a Antropologia, ciência do homem, tem-se preocupado principalmente com o estudo dos povos primitivos [os termos são da época]. Mas o homem civilizado é um objeto de investigação igualmente interessante e, ao mesmo tempo, sua vida é mais aberta à observação e ao estudo. A vida e a cultura urbanas são mais variadas, sutis e complicadas, mas os motivos fundamentais são os mesmos nos dois casos. Os mesmos pacientes métodos de observação despendidos por antropólogos tais como Boas e Lowie, no estudo da vida e maneiras do índio norte-americano, deveriam ser empregados ainda com maior sucesso na investigação dos costumes, crenças, práticas sociais e concepções gerais de vida que prevalecem em Little Italy, ou no baixo North Side de Chicago, ou no registro dos folkways mais sofisticados dos habitantes de Greenwich Village e da vizinhança de Washington Square em Nova York. (PARK, [1925] 1967: 27)
\end{abstract}

Em termos de coetaneidade, essas duas obras apontam em diferentes direções, mas estão em diálogo. É claro que a especialização na universidade implica campos diferenciados, mas talvez seja possível, a partir de algumas perspectivas, legitimar um campo novo, tal como foi batizado, com tom algo irônico, numa pesquisa recente que coordenei na Amazônia. Ao contar que fazia pesquisa com os Sateré-Mawé em Manaus, alguém disse: "então vocês fazem Etnologia Urbana?” Respondi: “É, é isso mesmo, Etnologia Urbana”. Talvez esse termo mostre um campo novo em que etnólogos e antropólogos urbanos podem dialogar3. O texto de Park mostra que não há uma diferença temporal muito grande entre as duas orientações na Antropologia, mas há diferenças, com certeza, de outra ordem.

Nós sabemos que a Antropologia construiu seu legado teórico e metodológico com base nos estudos sobre os chamados povos de pequena escala: indígenas, ribeirinhos, aldeias rurais, quilombolas e assim por diante. Desta forma, abre-se para nós, que trabalhamos com cidade, um desafio de como aplicar o que foi pensado com esse tipo de população para a cidade contemporânea. Há uma escala muito diferente. Mas, além de um desafio, pode ser uma hipótese: será que esse não é um diferencial, próprio da etnografia urbana para ver aquilo que passaria despercebido em outras ciências sociais? Será que a antropologia, mantendo-se fiel ao legado da etnologia junto aos povos de pequena escala pode apresentar um viés inovador em sua perspectiva? Essa é uma das hipóteses com que eu trabalho, empregar o método etnográfico para olhar a realidade das nossas grandes cidades contemporâneas.

A citação de Ezra Park nos leva aos primórdios da Antropologia Urbana, com a Escola de Chicago, na verdade uma escola sociológica. Mas Ulf Hannerz (2015) utiliza a expressão "os etnógrafos de Chicago", para se referir a uma série de pesquisadores dessa escola cujo trabalho se aproxima do método etnográfico. Como, por exemplo, o pesquisador que descobre cartas no lixo de imigrantes poloneses e as usa como recurso para a formação de dados (ZNANIECKI e THOMAS, 1918). Há, portanto, um investimento etnográfico da Escola de Chicago, que reuniu Sociologia e Antropologia e se tornou uma referência. Outra

3 Ainda que não haja, na atualidade, no Brasil, uma diferença substancial entre Etnologia e Antropologia, historicamente convencionou-se chamar de etnologia a antropologia feita junto às populações indígenas brasileiras, o que constitui o campo da Etnologia Indígena, em oposição semântica e disciplinar à Antropologia feita nas sociedades complexas, ou Antropologia Urbana. [Nota do Editor] 
referência é a Escola de Manchester, de pesquisadores britânicos, desenvolvida na perspectiva da chamada destribalização de povos africanos, no Copperbelt4. Seu trabalho também vai produzir uma reflexão sobre a presença dessas populações nativas nas cidades, como trabalhadores, buscando compreender se eles iriam ou não manter seu modo tradicional de vida no novo contexto urbano.

\section{Em São Paulo: ELSP e USP}

Essas duas escolas - tanto a Escola de Chicago, quanto a Escola de Manchester - são referências que fundamentam, de certa maneira, a perspectiva da Antropologia Urbana e, no caso brasileiro-paulista especificamente, é a Escola de Chicago que vai deixar sua marca. Isso se dá numa conjuntura especial, em São Paulo, a Revolução de 1932, em que os paulistanos são derrotados5. Nesse momento especial, o empresário e economista Roberto Simonsen cria a Escola Livre de Sociologia e Política (ELSP) para formar quadros tendo em vista as demandas de uma sociedade em transformação e, para tal, recorreu a professores norte-americanos. Personagem de relevo foi Donald Pierson que se incorpora em 1939 à Escola Livre de Sociologia e Política e, em 1941, cria a Divisão de Estudos Pós-Graduados. Foi um dos primeiros espaços institucionais de pesquisa, inclusive de pós-graduação, por onde passaram figuras ilustres da intelligentsia nacional: Florestan Fernandes, Darcy Ribeiro, Sérgio Buarque de Holanda, Oracy Nogueira, Antônio Cândido, um conjunto de pesquisadores importantes que começa a trabalhar na década de 1930.

É interessante notar que as primeiras pesquisas sobre padrão de vida e nível de consumo da classe trabalhadora urbana no Brasil foram coordenadas, na ELSP, entre 1934 e 1937, por dois pesquisadores norte-americanos, Horace Davis e Samuel Lowrie (cf. KANTOR, MACIEL \& SIMÕES (2001: 15), trabalho que deu a base para a formação do salário mínimo (LOWRIE, 1938). Cabe observar que intelectuais de outras linhagens e procedências, como Emilio Willems, Herbert Baldus e o antropólogo britânico E. E. Radcliffe-Brown, também fizeram parte dessa equipe.

Nessa busca de professores norte-americanos, houve, contudo, uma diferença. Chicago era uma metrópole que se transformava da noite para o dia, a partir das levas de imigrantes da Europa Central, ou mesmo do interior dos Estados Unidos, com forte presença do contingente negro. A cidade teve que enfrentar esse afluxo e os problemas daí decorrentes e a expressão que ficou consagrada foi a de "patologia social", com base na perspectiva da ecologia humana: grupos sociais lutando por um lugar ao sol, em busca de recursos para sobrevivência, trabalho, moradia numa cidade cuja escala não dava conta da crescente e desproporcional demanda.

Em São Paulo não foi exatamente isso que aconteceu, pois ainda não foi a capital que passava por transformações dessa monta: as mudanças ocorriam inicial e principalmente na área rural. Cabe lembrar, a propósito, o estudo clássico sobre as transformações do modo de vida do caipira paulista, de Antonio Candido (1964). Ele não se limita a descrever o modo de vida "rústico", mas como está se transformando em função de uma mudança estrutural. Outro autor, José de Souza Martins (1974), em um texto intitulado "Viola quebrada", temati-

4 Cinturão do Cobre, na África Central, formado por colônias britânicas. [N. do E.]

5 A Revolução Constitucionalista de 1932, também conhecida como Revolução de 1932 ou Guerra Paulista, foi o movimento armado ocorrido nos estados de São Paulo, Mato Grosso do Sul e Rio Grande do Sul, entre julho e outubro de 1932, que tinha por objetivo derrubar o governo provisório de Getúlio Vargas e convocar uma Assembleia Nacional Constituinte. [N. do E.] 
za justamente a ideia do caipira que chega a São Paulo e fica impressionado com as mudanças das quais ele é de alguma forma testemunha. Martins transcreve uma moda de viola intitulada "Bonde camarão"6: diante do bonde elétrico, da empresa estatal Light, pintado de vermelho, ele olha e pensa: como é que as pessoas entram naquilo? E se der um choque? A eletricidade é uma novidade para ele. Embora engraçada, a história mostra exatamente o que Antônio Cândido diz que começa a aparecer, a "mistura": dentro do bonde se acotovelavam o pastor protestante, o padre católico, ao lado de uma moça, de uma velha... Antonio Cândido e todos os autores - Gioconda Mussolini, Oracy Nogueira - aqui citados vão acionar as categorias da Escola de Chicago justamente para pensar essa passagem do tradicional/agrário para o moderno/urbano. Além disso, há outros trabalhos, os estudos de comunidade conhecidos não só em São Paulo, mas também na Amazônia, na Bahia: Charles Wagley (Uma Comunidade Amazônica, [1953] 1980) é uma das dessas referências.

Mas o que realmente importa é reconhecer que a Escola de Chicago e sua influência na Escola Livre de Sociologia e Política, a ELSP, foram importantes e se mantiveram no panorama até os anos 1950, em São Paulo pois, em 1934, é fundada a Faculdade de Filosofia da USP, com a vinda da missão francesa trazendo Claude Lévi-Strauss, Fernand Braudel, Jean Maugué, Roger Bastide, Pierre Mombeig. Assim, abre-se um campo de competição entre a Escola Livre de Sociologia Política e a então Faculdade de Filosofia, Letras e Ciências Sociais da USP. Nesta última, o tom que prevaleceu foi o da sociologia. Florestan Fernandes é a grande figura da Escola de Sociologia e as referências não são mais autores de estudos de comunidades e sim Karl Mannheim, Max Weber, George Simmel, autores que irão trabalhar com outro tipo de unidade, não mais aquelas dadas pela pesquisa de campo, comunidades tradicionais, mas as classes sociais, as grandes unidades. Florestan inclusive chega a dizer que os antropólogos são muito bons para fazer trabalho de campo, mas na hora de interpretar tem que ser sociólogo por conta das grandes categorias que aciona. Essa polêmica toda que ocorreu gerou uma discussão muito profícua e movimentou de certa maneira os antropólogos do departamento de Ciências Sociais da USP.

Nessa perspectiva, duas integrantes desse departamento reivindicam a Antropologia e seu método, a etnografia: Ruth Cardoso fez um trabalho com imigrantes japoneses e Eunice Durham com italianos. Inicialmente a ideia era de se trabalhar não com a cidade, como objeto de pesquisa, mas com determinados grupos, como, neste caso, imigrantes. Há uma reviravolta. É como se se deixasse de lado o velho esquema estrutural-funcionalista que assegurava a perspectiva na Escola Livre de Sociologia e Política. Ruth e Eunice começam a entrar em outro campo, ainda não hegemônico na Universidade de São Paulo, a periferia.

\section{A descoberta da periferia}

Esta começa a ser reconhecida, agora como sinal de uma nova conjuntura em São Paulo. Assim como para a Escola Livre de Sociologia Política a conjuntura foi a derrota da revolução constitucionalista, para o recorte da Antropologia Urbana, nos anos 1960, a conjuntura institucional, política e econômica é inaugurada pelo golpe militar de 1964. Há uma derrota da classe operária, de suas

${ }^{6}$ Trecho de Bonde Camarão: "Aqui em São Paulo o que mais me amola são esses bonde que nem gaiola. Cheguei, abriram uma portinhola, levei um tranco e quebrei a viola. 'Inda pus dinheiro na caixa da esmola! Chegou um véio se facerando. Levou um tranco e foi cambeteando. Beijou uma véia e saiu bufando. Sentou de um lado e garrou suando. Pra mor de o vizinho tá catingando". Composição: Cornélio Pires e Mariano da Silva. 
vanguardas, até então atuantes nos partidos, nos sindicatos, no chão de fábrica: agora há um refluxo. E para onde? Para o lugar de moradia, na periferia. Não significa que a periferia não existisse, mas agora começa a ter mais visibilidade porque há uma mudança estrutural. E essa periferia aparece como um lócus importante: não é mais o "dormitório", mas o espaço onde a política, em outros moldes, se refaz.

Tem-se, então, outro cenário e quem são os protagonistas? As mulheres; enquanto os maridos se dedicavam à "grande" política, eram elas que estavam no bairro. E fazendo o quê? Abaixo-assinados por creche, por iluminação, saneamento, organizando associações de bairro. Política também, só que em outra chave, era a micropolítica foucaultiana. Então, o que Eunice Durham nos mostrou não é que a antropologia fosse melhor, mas que seu objeto tinha se tornado visível. Portanto, aquilo que os antropólogos sempre fizeram, que é estudar parentesco, vizinhança, religião popular, festas populares, começou a aparecer como sendo um dado importante para conhecer que práticas são essas e quem são esses novos protagonistas e suas práticas.

É como se a antropologia fosse acionada agora para entender quem é esse novo ator social, suas táticas, alianças. Mas os métodos e o referencial teórico que se tinham estavam datados, pois agora havia coisas novas colocadas pelo campo. Os alunos de Ruth Cardoso e Eunice Durham, entre os quais me incluo, tiveram que começar a ler autores fora do círculo da antropologia. Começamos a ler Antonio Gramsci, Louis Althusser, Richard Hoggart, Manuel Castells, um grupo de autores que estava respondendo a questões que tinham a ver com a cidade. $\mathrm{E}$ assim começa a fazer sentido o conceito do direito à cidade, de Henri Lefebvre. Tivemos que construir de certa maneira um referencial novo. Com duas inovações: a do campo, do recorte empírico; e a busca, em outros autores, fora da antropologia clássica, de um referencial teórico para dar conta das novas demandas de estudo. É como se os atores sociais colocassem para os pesquisadores questões novas, além daquelas tradicionais da imigração, das relações raciais. Agora tem-se também a questão da moradia, o lugar onde as pessoas vivem o seu cotidiano, da sociabilidade no bairro, a religiosidade, o lazer.

Ruth Cardoso e Eunice Durham fizeram realmente uma mudança, sugerindo outros autores que não os clássicos da antropologia nas "reuniões das segundas-feiras", como chamávamos nosso encontro semanal. Elas começam a formar pesquisadores que foram depois para outras universidades: Gilberto Velho, Giralda Seyferth, Lygia Sigaud, Regina Novaes, Alba Zaluar, entre outros: como se pode ver, um conjunto de antropólogos do Rio de Janeiro fizeram sua iniciação em São Paulo. A brincadeira que corria era que, enquanto em São Paulo o nosso recorte empírico era a periferia, no Rio de Janeiro foram " $a x$ camadax médiax". Alba Zaluar e outros autores também fizeram incursões em regiões periféricas no Rio de Janeiro, mas nesse momento era: periferia e os "manos" em São Paulo e, no Rio, as camadas médias.

Com isso nos diferenciávamos um pouco, mas havia uma referência comum muito importante, a partir dessas duas professoras, ao abrir e legitimar um campo novo da antropologia urbana no Brasil. Há outros autores que citaremos aqui, mas temos uma perspectiva, a partir de uma conjuntura política, econômica e cultural muita definida. No Rio, em termos da Escola de Chicago, Gilberto Velho deu muito mais ênfase, por exemplo, ao trabalho de Erving Goffman, ou seja, a própria Escola de Chicago foi lida em chaves diferentes. No Rio Grande do Sul, na UFRGS, Ruben Oliven esteve explorando também outras linhas de pesquisa, como os processos de urbanização. 


\section{O circo-teatro}

É nesse contexto - de estudos sobre o modo de vida dos trabalhadores, seus movimentos sociais e formas de sociabilidade - que se insere minha trajetória. Na verdade, escolhi um tema aparentemente sem muita importância, uma forma de dramaturgia popular, o circo-teatro, que resultou em minha tese de doutorado e posteriormente no livro Festa no pedaço: cultura popular e lazer na cidade (MAGNANI, [1984] 1998). Era um tema aparentemente fora do padrão porque, com tantos problemas ditos sérios para estudar, resolvi pesquisar uma manifestação cultural popular de entretenimento. Ruth e Eunice acolheram minha proposta, mas tive que fazer um esforço adicional, que depois serviu de alerta para meus orientandos: como meu tema parecia "desimportante", o desafio foi torná-lo relevante no projeto e bem embasado para a Fapesp ${ }^{7}$ financiarme pelo prazo de quatro anos.

A estratégia foi argumentar que o circo-teatro era uma forma de cultura popular que remetia à Commedia dell'arte do século XVI, ao melodrama do século XIX e ao surgimento do romance de folhetim. Quem me ajudou a fazer isso foi Marlyse Meyer, uma professora de Letras na USP que trabalhava com esses temas. Ela tinha um grupo chamado "Altos e Baixos Estudos" que era para estudar justamente a relação entre a "alta" e a "baixa" literatura - parodiando o célebre Institut de Hautes Études. Com esse tema, começa a emergir a questão da relação entre trabalho e tempo livre. Como ocupam o tempo liberado das obrigações do trabalho? A partir de então, como desenvolvo na tese e mostro no livro, surge a noção de pedaço. Era necessário ter uma questão teórica no projeto: a cultura popular é conservadora ou progressista? Essa era a pergunta porque na época a discussão era "cultura e ideologia", não se podia escrever um texto que não tivesse essa chave. Coloquei essa chave, era minha hipótese, e fui com ela para campo. E quando a levei, ouvi: "professor, pouco importa se o circoteatro é conservador ou não, ele é um bom lugar para a gente se divertir e se encontrar". Com isso, a linha de discussão seguiu outro rumo.

Por conta dessa descoberta, incentivava meus alunos: façam um bom projeto, com hipótese, objetivos, bibliografia atualizada, tudo direitinho, mas com a secreta esperança que, em campo, algo mude, pois, a experiência aí é muito rica, surpreendente e mais viva do que se imagina. Se percebermos a mudança, talvez descubramos algo novo, do contrário, faremos aquilo que estava no projeto, que também é bom: tem teoria, tem discussão. Eu poderia ter feito uma tese sobre "o teatro", "o circo-teatro" como uma manifestação popular de cultura e um gênero literário e dramático muito importante. No entanto, meus interlocutores me apontaram outra direção e eu segui.

Ao seguir essa nova pista, abriu-se um panorama completamente novo para a pesquisa, minha e de outros acadêmicos. Contarei um pouco dessa trajetória, pois ela comprova a importância da etnografia. Se nos deixarmos afetar pelo campo, como afirma Jeanne Favret-Saada (2005), levando a sério o que eles, nossos interlocutores em campo, dizem e fazem, é muito provável que haja uma nova perspectiva, que se pode seguir ou não. Seguindo-a, é provável que se chegue a novas conclusões, tanto teóricas quanto metodológicas, não previstas.

As ferramentas de pesquisa também são construídas em campo. Foi o que sucedeu, em meu caso, com o pedaço, aparentemente um termo trivial que, para ser transformado em categoria de análise, foi necessária uma discussão com $A$

\footnotetext{
7 Fundação de Amparo à Pesquisa do Estado de São Paulo.
} 
Casa e a Rua, de Roberto DaMatta (1997). De uma dicotomia, surgiu um triângulo: entre a casa e a rua, imiscuiu-se o pedaço, uma outra forma de encontro que surgiu da pesquisa. Com efeito, a casa é o lugar dos parentes e a rua o lugar dos estranhos, do perigo, da violência, mas também das oportunidades. O pedaço, contudo, é um lugar intermediário, do encontro entre os iguais, os "chegados", para a sociabilidade, para a festa, a troca de ideias; lembra a expressão que dá o título ao livro de William Foote-Whyte ([1943] 2005), Sociedade de Esquina.

\section{Da periferia ao centro}

Prosseguindo com a trajetória: a noção de pedaço serve para registrar uma forma de sociabilidade encontrada na periferia, mas será que funciona em outros contextos? Em meu livro Da periferia ao centro: Trajetórias de pesquisa em Antropologia Urbana (2012), descrevo essa passagem. Era um desafio, ficou muito mais complicado, pois se na periferia era possível identificar comunidades, bairros, vizinhança, no centro de São Paulo, com toda sua diversidade, esse insight parecia pouco adequado. Estava diante da metrópole e logo veio à mente um trecho de Edmund Leach (1989: 50-51):

Defendo que os conhecimentos dos antropólogos sociais têm uma qualidade especial,
devido à área onde exercitam sua imaginação artística. Essa área é o espaço de algu-
ma pequena comunidade de pessoas que vivem juntas em circunstâncias em que a
maior parte de suas comunicações diárias depende diretamente da interação. Isto não
abrange toda a vida social humana, muito menos abrange toda a história humana.
Mas todos os seres humanos gastam grande parte de suas vidas em contextos desta
espécie.

Esta observação de Leach mostra como nós antropólogos nos movemos melhor no seio da comunidade, em contato direto e cotidiano com os interlocutores, fazendo a observação participante. Seria possível transpor essa inserção ao contexto de uma grande cidade? Difícil. Denominei essa tentativa de a "tentação da aldeia”, ou seja, tomar São Paulo como uma aldeia que cresceu demais ou considerá-la como um conjunto de aldeias em cujos limites se faria a observação: um terreiro de umbanda ou candomblé, a festa de Nossa Senhora Achiropita, uma associação de moradores, um coletivo de jovens.

Seria como repartir a metrópole em pequenas comunidades, fazer a imersão e ficar especialista em cada uma delas. Será que isso resolveria? Seria a tentação de reduzir a escala da metrópole a comunidades, como aponta Leach. A outra tentação seria ficar no plano das generalidades, levando em conta apenas as grandes variáveis macroeconômicas e demográficas para explicar a diversidade e complexidade da metrópole. É a perspectiva macro, que fica no outro extremo, um olhar que denomino "de longe e de fora". A outra, micro, será "de perto e de dentro", própria da etnografia. Não que se oponham, mais bem complementam-se.

Um trecho do livro de Evans-Pritchard (1978 [1940]:20) descreve sua estada em campo: "da porta da minha barraca podia ver o que acontecia no acampamento ou aldeia e todo o tempo era gasto na companhia dos Nuer”. A propósito desta observação, escrevi o seguinte em Na Metrópole (MAGNANI, 1996: 19-20): "Se essa passagem constitui a imagem clássica da pesquisa de campo, nada mais distante, então, das condições de trabalho de um antropólogo às voltas com questões e problemas característicos das modernas sociedades urbano-industriais, cujo campo é a cidade: da janela de seu apartamento não tem diante de si o espetáculo da vida social em sua totalidade e, mesmo que conviva 
mais intensamente com o grupo que está estudando, nem sempre gasta todo o tempo em sua companhia"

Se o antropólogo urbano não tem exatamente esse convívio como descrito por Evans-Pritchard - e também por Malinowski, com os Trobriandeses - ele está diante de um desafio, pois não pode ignorar todo um legado teórico/etnográfico deixado pelos nossos ancestrais da antropologia. Qual seria a saída? A saída seria encarar a pesquisa de campo, nesses contextos complexos Chicago, São Paulo, Cuiabá - com base na etnografia, entendida como o olhar "de perto e de dentro", mas sem cair na fragmentação. Para isso, é preciso também levar em conta o outro polo da observação: “de longe e de fora”. Nesses contextos, não há comunidades isoladas - aliás, mesmo outros grupos estudados pelos etnólogos, ribeirinhos, quilombolas, indígenas, não configuram comunidades isoladas.

A Antropologia Urbana se consolidou para dar conta das formas de apropriação e circulação por territórios mais amplos e densos. E como é que se escapa da fragmentação? Pela construção das categorias de análise, como a do pedaço, elaborada para dar conta de uma sociabilidade típica da vizinhança na periferia. No entanto, ao tentar aplicar em outro contexto, no centro da cidade, foi preciso fazer ajustes.

O primeiro lugar que onde a pus à prova foi a "Galeria do Rock", no centro antigo, um bom lugar para fazer o teste em razão da presença ali de jovens, com venda de discos, anúncios de baladas, cabeleireiros afro. Havia jovens de Guaianases, de Santos, de Carapicuíba, da zona leste, zona norte. Diferentemente dos pedaços lá na periferia, contudo, onde as pessoas se conheciam por vínculos de parentesco, de vizinhança, preferências por times de futebol, pela origem - pois vinham do interior de São Paulo, do Norte, do Nordeste -, aqui não se conheciam. Num primeiro momento concluí que eram situações muito diversas, mas, nada de desistir. Fui mais uma vez e outra e, à medida em que percorria a Galeria do Rock, comecei a descobrir algo que tinha passado despercebido: sim, podia ser que eles não se conheciam, mas se reconheciam. Porque a logomarca da banda na camiseta era a mesma, as posturas corporais conversavam, a trancinha no cabelo dos meninos e meninas negras que iam ali para fazer e demandava horas: era uma boa ocasião para eles se encontrarem e marcarem o próximo encontro quando ia ter hip hop, em alguma quebrada.

Então, era um lugar onde havia pessoas que se reconheciam como participantes do mesmo grupo. Com vários pedaços ali dentro, aquilo era uma mancha: foi assim que apareceu essa nova categoria. As demais foram surgindo à medida em que a etnografia ia encontrando obstáculos e tentando superá-los; essas categorias não são inventadas pelo pesquisador, é no diálogo com os interlocutores e suas práticas que elas emergem.

\section{As categorias}

Desta forma, depois da categoria pedaço, trabalhei com as de mancha, trajeto, pórtico e, finalmente, circuito, categorias essas que me permitiram pensar a diversidade no campo, a heterogeneidade dos equipamentos e a criatividade dos atores sociais. Os decantados desencontros e anonimato dos moradores de uma metrópole como São Paulo podiam ser contestados na perspectiva do olhar "de perto e de dentro". É possível identificar, por exemplo, o "circuito gay" na cidade, mas, se a observação ficar restrita ao Largo do Arouche, por exemplo, tem-se uma mancha onde se encontram diferentes grupos, com predominância 
dos "ursos". No circuito gay em São Paulo, nem todo mundo se conhece, mas está pontilhado por manchas e percorrido por trajetos. É por onde os diferentes grupos podem circular: eles têm lugares em São Paulo que os acolhem. Sendo gay é possível ir a um lugar onde não se é conhecido, mas se chegar lá, há um reconhecimento. Desse modo, as categorias permitiram mostrar que a cidade não é fragmentada, que os atores sociais circulam com regras definidas e que para poder descobrir essas regras é necessária uma observação atenta e continuada. A ideia do "de perto e de dentro" é observar de que maneira eles constroem e compartilham sua sociabilidade. E assim com os demais grupos e coletivos urbanos.

Todas essas categorias foram construídas para dar conta justamente da heterogeneidade com a qual as ciências sociais em geral classificam as grandes metrópoles, enfatizando o desencontro, a violência, a falta de comunicação. Ao olhar um pouco mais "de perto" percebe-se que há redes que funcionam e foi isso que as categorias colocaram em evidência. Mas se categorias de análise emergem das exigências do campo, sua consolidação e aplicação mais ampla dependem de uma reflexão teórica. Num primeiro momento, como foi mencionado mais acima, o pedaço teve que ser pensado com base em um aporte de DaMatta, "a casa e a rua" - que, aliás, não foi descoberto com observações no Rio de Janeiro mas com entre os Apinajés ${ }^{8}$.

Assim, na continuação, outro autor entra na discussão, Marc Augé (1992), não por seu conceito de "não lugar", mas o de "lugar antropológico", que por sua vez recorre a uma ideia do historiador Pierre Nora (1984), "lugar de memória". Se o "lugar de memória" é privilegiado para uma pesquisa, por concentrar múltiplos significados, o "lugar antropológico" também o é, pois se trata de uma situação que faz sentido para os atores sociais envolvidos e, ao mesmo tempo, um lugar de inteligibilidade para o pesquisador. Nesses lugares, as categorias têm uma espécie de double face, pois, se fazem sentido naquele contexto - como o pedaço, em determinada região da vizinhança -, ao transcender o contexto original e "forçando" um pouco, é possível, como "unidade de inteligibilidade", ser aplicada em outro contexto.

Se, numa primeira aproximação, tais categorias são suscitadas com base na pergunta que se faz em campo, no convívio e no diálogo com os atores sociais, há um outro aspecto, que Marilyn Strathern (2014) chama de "momento etnográfico": além da etnografia propriamente dita, em campo, há o labor da sua escrita; não significa que primeiro descobre-se o dado que depois é pensado e registrado em texto. O "momento etnográfico" articula ambos os lados.

\section{Os surdos}

Cabe agora passar para casos concretos e o primeiro exemplo está no livro Da Periferia ao Centro (MAGNANI, 2012), uma pesquisa que eu e alguns orientandos fizemos com surdos na cidade de São Paulo. A ideia e o convite partiram de pesquisadores em Linguística da FFLCH/USP, Evani Viotti e Leland McCleary, que estavam trabalhando com a língua brasileira de sinais (LIBRAS). Mas, e os próprios surdos? Onde vivem? Por onde circulam? Estas e outras questões, mais afeitas à Antropologia, foi nossa contribuição. Então o pessoal da Linguística sugeriu uma parceria com o Núcleo de Antropologia Urbana para cobrir esse aspecto - afinal, somos vizinhos de prédio e nem sempre ocorrem essas colaborações. 
E lá fomos nós, em 2002, no mês de junho, uma boa ocasião para fazer a pesquisa pois acontecem muitas festas juninas: o Brasil inteiro se veste com roupa remendada, chapéu de palha, canta música caipira nas esquinas, nas igrejas, nas universidades, nas empresas. E logo surgiu uma pergunta: será que surdo também faz festa junina? E mais: festa junina de surdo tem música? Embalados por essas questões - nada teóricas, por enquanto - fomos a campo e participamos de uma festa junina de rua, organizada pela ADEFAV9, com fogueira, com a presença de surdos, pais, mestres e outras pessoas com necessidades especiais.

Lá conhecemos Claudia Sofia, uma jovem surda e cega. Realmente o campo se abre para coisas inesperadas: quando é que teríamos contato com uma surda e cega? E que se comunica? Essa moça ficou surda já adolescente, depois de adquirir a linguagem, ou seja, não se trata de uma surda de nascença, que não consegue falar. Na verdade, ela fala porque, como todos, teve o estímulo da escuta, ao passo que o surdo de nascença não fala, não porque é mudo, mas porque não recebeu nenhum estímulo sonoro: por isso é que a expressão surdomudo é inadequada. Mas, se também ela não consegue enxergar, não poderia fazer uso da língua de sinais, que é um verdadeiro teatro com as mãos. Como é que se comunicava? Ela chegou perto de mim e botou os dois dedos na comissura dos meus lábios e a outra mão na garganta para sentir a vibração das cordas vocais e com isso conseguia captar, pelo tato, os sons da fala. Eu falava normalmente e ela decodificava todos os meus fonemas.

Fiquei surpreso: não tinha a menor ideia que isso existia. Ela entendia tudo e eu podia falar normalmente enquanto ela colocava a mão nos meus lábios e a outra mão no meu pescoço para sentir a vibração. Lia com as mãos no meu corpo, "escutando" o que eu estava dizendo. Fiquei maravilhado"10.

A partir dessa primeira festa ficamos sabendo de outra, para onde também levei meus alunos. Seria uma festa junina de surdos na igreja de Santa Teresinha das Irmãs Camilianas, onde há uma escola bilíngue de ensino fundamental e médio para surdos. Lá, deparamo-nos com mais ou menos cinco mil surdos de São Paulo e de outras partes: chegavam vários ônibus. Era uma festa tradicional sobre a qual nenhum de nós tinha a menor ideia e a dúvida era: como é que a gente se comporta? É mais ou menos quando um etnólogo entra pela primeira vez em uma aldeia indígena cuja língua não conhece. Mas era um momento privilegiado para deixar-se afetar. E cometi algumas gafes: se passar na frente de dois surdos conversando, é como se colocasse a mão na boca dos falantes porque os impede de ver os sinais. Deslize após deslize, chegou uma hora em que resolvi: "vamos ver de longe, porque de perto não estou entendendo nada. Um pouco de longe, talvez".

Subi até a arquibancada - pois era uma quadra poliesportiva -, lá de cima, fiquei contemplando e logo me veio uma metáfora: "Mar de mãos", porque eram as mãos que se moviam para conversar e não havia muito ruído. Havia algum barulho, evidentemente, música, pois parentes, amigos e professores ouvintes também estavam lá, mas não como numa festa comum de falantes. Desta forma, tive, assim, a experiência etnográfica, uma experiência meio "epifânica", porque não sabia o que iria ocorrer e deixei-me entrar em contato com a dinâmica

9 Centro de Recursos em Deficiência Múltipla, Surdocegueira e Deficiência Visual, de São Paulo, organização sem fins lucrativos que promove programas nas áreas de assistência social, saúde e educação, fundada em 1983. [N. do E.]

10 Essa modalidade de comunicação é denominada tadoma e foi desenvolvida pela professora de duas crianças, Tad e Omã (daí a denominação) que ficaram surdocegas em decorrência da síndrome de Usher, tipo de surdez congênita seguida ou não de perda de visão a qual ocorre, geralmente, em idade mais avançada. O tadoma também foi utilizado por Helen Keller [escritora, conferencista e ativista social norte-americana, a primeira pessoa surdocega da história a conquistar um bacharelado, N. do E.] para se comunicar em inglês quando veio ao Brasil em 1953. 
da festa. Comecei a perceber o corpo deles como meio de expressão. Um deles, em algum momento disse - evidentemente em Libras, mas com a tradução de um intérprete -: "Professor, vocês ouvintes falam com essa coisinha pequeninha aqui e escutam por essa orelhinha. Nós com o corpo inteiro, o nosso corpo é o nosso órgão de comunicação". Outro tipo de festa que eles frequentam são as raves, todo aquela barulheira é sentida como vibração.

A pesquisa, então, estava indo de vento em popa, já tínhamos identificado um pedaço na festa de rua e agora uma mancha nesta última, o Instituto Santa Teresinha, pois não havia apenas surdos, mas pais de surdos, namorados de surdos, professores, antropólogos, muita gente. Enfim, um lugar que acolhe pessoas que não necessariamente se conhecem, mas participam de um mesmo interesse. $\mathrm{E}$ a rede foi se abrindo: ficamos sabendo de mais um encontro, a festa do "cowboy surdo", semanas depois no bairro Vila Olímpia, perto do aeroporto de Congonhas: "Nossa, perto do aeroporto, com barulho de avião?" Para um ouvinte era um problema, mas para eles, logicamente, nada.

Cheguei com antecedência, segundo outra regra do etnógrafo em campo: tem de estar antes de a festa começar e sair depois, para captar o conjunto todo. Estava lá cedo, mas meus companheiros de pesquisa, não. Era um sobrado. Apresentei-me para a pessoa da recepção que, evidentemente, era surdo, mas versado na leitura de lábios, entendeu-me perfeitamente. Lá dentro procurei uma cadeira, em posição estratégica, sentei e fiquei observando atentamente a movimentação. O intérprete de libras também não chegava: dependia dele, pois não domino a língua de sinais - e nada de ele aparecer. Eu olhava no relógio, a festa rolando, os surdos passavam, me encaravam. Fui até a cozinha, comprei uma cerveja, voltei; em certo momento despencou um quadro na parede, apressei-me em ajeitá-lo, um rapaz me ajudou, trocamos um sinal. Voltei para o meu lugar, não conseguia uma inserção melhor. Se a festa junina dos surdos no Instituto Santa Teresinha foi um sucesso etnográfico, aqui todo o contrário. Foi dando aquele desespero, sentindo-me um intruso no pedaço.

Resolvi esperar mais um pouquinho, fiquei esperando e nada, não chegava ninguém. Então decidi ir embora, reconhecendo que desta vez não deu certo, talvez a aventura etnográfica com os surdos terminava ali, tinha lá suas complicações, para fazer pesquisa com surdos eu teria de ser expert na língua de sinais. Começa o discursinho interno durante a viagem de volta. Mas ao término de uma jornada em campo, seja lá o que tenha acontecido, qual a tarefa? O relato de campo. Sentar e escrever, começando com o cabeçalho: "Dia tal, nome do evento, endereço, participantes, autor do relato”. E começa o relato, cheguei tal hora: aconteceu isso e aquilo, o quadro caiu, e assim por diante.

À medida em que eu fui lembrando detalhes aparentemente sem relevância, chegou um momento em que surgiu aquele insight, lembrei da Marilyn Strathern e do momento etnográfico: lá, eu estava no meio dos surdos da mesma forma como eles estariam no meio dos ouvintes/falantes; pude sentir no meu corpo o que seria, por exemplo, o que um surdo sentiria, aqui, assistindo a esta conferência sem intérprete. Estaria como eu estava entre eles, completamente deslocado. Pois eu estava no pedaço surdo e este é o espaço dos iguais, deles, os surdos. Esse insight surgiu, não na hora do campo, mas na hora da escrita, parte do "momento etnográfico".

Assim as categorias vão aflorando: descobri algumas manchas de surdos na cidade, percorri alguns trajetos seus, um circuito foi se delineando: a cidade dos surdos, uma cidade lida e percorrida a partir desses atores sociais. A pesquisa seguiu, eu não tinha a menor ideia que, para além da "deficiência", existia esse 
verdadeiro modo de vida nesta cidade uma cidade dos surdos. Há barzinhos de surdos, de surdos gays; no shopping Santa Cruz eles se encontram na praça de alimentação, só para conversar. Missas de surdos: como se sabe, há um momento em que os devotos se abraçam, se cumprimentam desejando "a paz do Senhor esteja convosco". Demorava bastante essa parte pois eles aproveitavam para conversar, para se encontrar, para se expressar, para olhar um para outro. E o padre, surdo também, pacientemente interrompia a celebração, ou seja, o ritmo da missa dos surdos é outro.

Em resumo, comecei, com meus orientandos - um deles concluiu seu doutorado ${ }^{11}$, outra fez o mestrado e um aluno de graduação, iniciação científica - a entrar no que Howard Becker denomina o "mundo das artes", (1982) neste caso, no mundo dos surdos. A cidade de São Paulo, para eles, é uma outra cidade. E assim, há muitas cidades na mesma cidade.

\section{Cidade, unidade de análise?}

A seguir, mais dois exemplos de pesquisas por mim orientadas que reforçam o que venho demonstrando. Giancarlo Machado, atualmente professor na Universidade Estadual de Montes Claros (Unimontes/MG), defendeu sua tese sobre o skate em São Paulo (2017). E para manter o bordão, a cidade de São Paulo, lida na chave do skate, é outra. A região que ele escolheu para fazer a pesquisa foi a praça Roosevelt, um lugar que estava abandonado e fica bem no centro tradicional, endereço de muitos grupos de teatro no seu entorno. É também um espaço usado por moradores de rua e que foi recentemente revitalizado pela prefeitura, com muitos bancos de concreto. Os skatistas descobriram que os bancos eram muito bons para fazer manobras, seus "picos”, não sem alguma tensão, pois às vezes havia idosos sentados, o que demandava uma negociação para compartilhar o espaço. Além do mais, era um lugar em que mães e babás levavam as crianças para brincar, passeadores levavam os pets, além dos idosos e skatistas. Ademais dessa praça, existem pistas feitas pela prefeitura, mas skatista que se preza acredita que quem vai em pista é "pistoleiro", um termo pejorativo. Os mais ousados procuram o vão do MASP, corrimão de banco, enfim, exploram outros espaços. São exemplos de "contra-usos" da cidade. Além do mais, o autor - que na tese faz uma interessante comparação entre o caso de Barcelona ("a meca do skatista") e São Paulo - distinguiu os que usam seu equipamento para ir ao trabalho e os que o fazem por lazer. Mais um exemplo de que São Paulo, na ótica desses atores sociais, é lida e apropriada em outra chave.

Mariana Machini (2017), por sua vez, defendeu uma dissertação de mestrado sobre hortas urbanas em São Paulo. Pode parecer algo exótico, "plantar alface" na Praça do Ciclista ${ }^{12}$, na Avenida Paulista e outra no Centro Cultural de São Paulo: iniciativas de alguns abnegados defensores do meio ambiente? Mariana, contudo, mostrou um verdadeiro circuito de hortas urbanas, permeado com discurso político e de lazer também, pretexto e motivo para encontros e discussões. Quem cuida delas? Quem pode usufruir? Qualquer transeunte? Moradores de rua? Há uma discussão sobre a cidade, sobre o espaço público, sobre direitos, a partir da horta urbana. Dessa maneira, não se trata de exotismo de uma classe média intelectualizada.

${ }^{11}$ Publicado com o título Cultura Surda, de César Augusto de Assis Silva, 2012.

12 Praça do Ciclista é o nome dado ao espaço de canteiro central da Avenida Paulista, na cidade de São Paulo, situado entre as ruas Bela Cintra e Consolação. [N. do E.] 
A partir desses temas, bem localizados, surgiu uma questão mais geral: afinal, a cidade é uma unidade de análise? Se para os planejadores, os responsáveis pelo Plano Diretor, por exemplo, talvez seja, não há como não levar em conta sua diversidade - as várias cidades que abriga - o que desafia projetos abrangentes. Os responsáveis pela administração, seja em São Paulo, Cuiabá ou outra cidade, têm que discutir com os atores sociais o que exige canais de comunicação e participação.

Mas afinal, pode-se tomar a cidade como uma totalidade, de contornos e limites bem precisos e, portanto, como unidade de análise? A propósito agora destaco dois textos: um é de Lévi-Strauss, o outro de Jurgen Habermas. O primeiro está no livro Tristes Trópicos (1996) e corresponde ao tempo em que lecionou na USP, como professor de filosofia e sociologia, integrante da chamada missão francesa, na década de 1930. Antes de vir, tinha a expectativa de encontrar indígenas nos arredores da cidade. Como isso não aconteceu, então, juntamente com sua mulher na época, Dina Lévi-Strauss ${ }^{13}$, aproveitava os fins de semana para fazer o que denominou "etnografia dos domingos": observar manifestações de cultura popular tradicional como as festas de São Gonçalo, Folia de Reis, do Divino. Dina colaborou com Mario de Andrade na Sociedade de Etnologia e Folclore de São Paulo da Secretaria de Cultura.

No começo de Tristes Trópicos, há tópicos muito reveladores sobre a questão da cidade. Lévi-Strauss finalmente conseguiu seu intento de entrar em contato com populações indígenas e, no percurso para o sertão, em direção a Mato Grosso, onde se encontraria com os Nhambiquara e Bororo, cruza o interior de São Paulo e passa pelo norte do Paraná. Aí se defronta com cidades recémcriadas pela Companhia de Colonização Norte do Paraná. Não eram cidades marcadas pelo estilo "crescimento orgânico", mas surgidas da noite para o dia, planificadas, organizadas. Vieram à sua mente indagações:

\begin{abstract}
Que misteriosos elementos, perguntava-se Lévi-Strauss, seriam responsáveis por esses quadriláteros onde as ruas são todas iguais, em ângulo reto? Não escapava à sua observação, porém, o fato de que algumas eram centrais, outras periféricas; ora perpendiculares à linha ferroviária ou à estrada, ora paralelas. Por sobre a grade das combinações possíveis distribuíam-se as conhecidas funções urbanas do comércio, dos negócios, da moradia e dos serviços públicos. Algumas situavam-se preferencialmente no sentido do tráfego enquanto outras procuravam as transversais. (MAGNANI, 2012: 282).
\end{abstract}

Em seguida, estabelece comparações com o caso de ruínas urbanas na Índia:

No vale do Índus, perambulei por aqueles austeros vestígios que os séculos, os areais, o salitre e as invasões arianas deixaram subsistir da mais antiga cultura do Oriente: Mohenjo Daro, Harappa (...). Que desconcertante espetáculo o desses antigos casarios! Ruas traçadas a régua e cruzando-se em ângulo reto; bairros operários de casas idênticas; oficinas industriais para a moagem de farinhas, fundição e cinzelamento de metais (...); banhos públicos, canalizações e esgotos (...). Nenhum monumento, nenhuma grande escultura (...).

Gostamos de imaginar que, ao fim de 4 ou 5 mil anos de história um ciclo se encerrou; que a civilização urbana, industrial, burguesa, inaugurada pelas cidades do Índus, não era tão diferente, em sua inspiração profunda, daquela fadada, após uma longa involução na crisálida europeia, a alcançar a plenitude do outro lado do Atlântico. Quando ainda era jovem, o mais Velho Mundo já esboçava o semblante do Novo. (LÉVI-STRAUSS, 1996: 122)

\footnotetext{
${ }^{13}$ A antropóloga Dina Lévi-Strauss (1911-1999) foi casada com Claude Lévi-Strauss de 1932 a 1939 e esteve no Brasil com ele em todo seu percurso, inclusive nas viagens que deram origem ao livro Tristes Trópicos, em que sociedades indígenas de Mato Grosso são etnografadas. Apesar de ser citada apenas uma vez na obra, sua contribuição nas pesquisas é inegável e foram reconhecidas nas exposições realizadas mais tarde em Paris. [N. do E.]
} 
Vale a pena, então, comparar essas observações com uma (longa) citação de Jurgen Habermas (1992 [1981]: 123), a partir de outra etapa da urbanização, as cidades da Idade Média:

\begin{abstract}
As marcas da cidade ocidental, como Max Weber a descreveu, da cidade burguesa na Alta Idade Média europeia, da nobreza urbana na Itália do norte renascentista, da capital dos principados, reformada pelos arquitetos barrocos da casa real, estas marcas históricas confluíram em nossas cabeças até formarem um conceito difuso e multiestratificado. Este pertence ao tipo identificado por Wittgenstein como parte dos hábitos e da autocompreensão da prática cotidiana: nosso conceito de cidade liga-se a uma forma de vida. Esta, contudo, se transformou a tal ponto que o conceito dela derivado já não logra alcançá-la. (...). Enquanto um mundo abarcável, a cidade pôde ser arquitetonicamente formada e representada para os sentidos, o que quer dizer que as funções sociais da vida urbana - nos seus aspectos econômicos, políticos, culturais, de práticas religiosas, da vida cotidiana no âmbito do morar, da recreação, da festa podiam ser vivenciadas e percebidas num marco temporal e espacial claramente configurado. Contudo, já no século XIX ao mais tardar, a cidade torna-se ponto de intersecção de relações funcionais de outra espécie. As próprias estações ferroviárias, por exemplo, já não permitiam a apreensão do tráfego ao longo de suas linhas, muito diferente da "clareza com que outrora os portões da cidade sugeriam as ligações concretas com as vilas adjacentes e a cidade mais próxima”. A vida urbana é cada vez mais mediada por "conexões sistêmicas não configuráveis" e "as aglomerações urbanas emanciparam-se do velho conceito de cidade o qual, no entanto, se apega nosso coração”.
\end{abstract}

Habermas levanta a discussão sobre esse tipo de cidade que não existe mais, porque de certa maneira transbordou os limites daquele modelo weberiano da cidade medieval e a pergunta é: será que ainda funciona o conceito de cidade? Dou sequência a esta provocação de Habermas, discutindo o próprio conceito de cidade com a ideia do "infinitesimal" de Lévi-Strauss, para pensar como é que poderíamos trabalhar com uma metodologia que desse conta dessa multiplicidade dos atores sociais:

\footnotetext{
Mas a vida urbana oferece um estranho contraste. Conquanto represente a forma mais completa e mais requintada da civilização, pela excepcional concentração humana que promove num pequeno espaço e pela duração de seu ciclo, ela precipita em seu crisol atitudes inconscientes, cada uma delas infinitesimal, mas que, em virtude do número de indivíduos que as manifestam por motivo idêntico, se tornam capazes de gerar grandes efeitos. (LÉVI-STRAUSS, 1996: 115)
}

Então, nesse ponto, a pergunta é: a cidade é uma unidade de análise? Podese encará-la como ponto de partida? Ou é melhor trabalhá-la como ponto de chegada? Essa discussão vai engendrar uma dicotomia: antropologia na cidade ou da cidade? Antes, mais um experimento etnográfico.

\title{
Da metrópole à aldeia: experimentos etnográficos
}

A discussão anterior teve como referencial empírico práticas na cidade de São Paulo: surdos, skatistas, gays, coletivos de jovens, hortas urbanas, entre outras. A multiplicidade dessa cidade permite construir recortes muito interessantes para colocar as categorias em xeque e ampliar seu alcance. O desafio é, e se forem aplicadas em outras cidades, com escalas diferentes? Cidades de porte médio, pequenas ou até mesmo outros tipos de assentamento urbano? Foi o que ocorreu por ocasião de um convite que me foi feito, para participar de um projeto do PROCAD (Programa Nacional de Cooperação Acadêmica/CAPES), entre a pós-graduação de Antropologia da USP e a pós-graduação da UFAM, Universidade Federal do Amazonas. O PROCAD permite a um programa de pósgraduação consolidado fazer parceria com outro que está começando para intercambiar professores e alunos. E o convite levou-me a participar do projeto idea- 
lizado por colegas etnólogos do Departamento de Antropologia da USP. Eles acrescentaram ao projeto, "Paisagens Ameríndias", um tópico de antropologia urbana com o objetivo de incluir a questão da presença de indígenas na cidade. Mais ou menos como aconteceu com os surdos quando os linguistas chamaram os antropólogos para colaborar, abrindo-se uma oportunidade para testar as categorias.

O desafio era duplo: etnologia indígena não é meu campo de pesquisa e nunca antes estivera em Manaus. Desafio aceito, fui com meus alunos fazer a pesquisa lá, uma nova experiência etnográfica, contando com a ajuda dos etnólogos do nosso departamento e os da UFAM. Não fomos assim completamente tábula rasa, mas a nossa experiência era reduzida com relação ao tema. O primeiro grupo com que entramos em contato foram os Ticuna que logo disseram: "não, nós não vamos mostrar nada, vocês vêm aqui, fazem pesquisa, escrevem tese e nunca mais voltam”. Mas há muitos povos indígenas morando em Manaus. Então, uma freira entrou em contato conosco (imprevistos no trabalho de campo): "ah, vocês estão querendo fazer pesquisa com índios. Eu conheço lá no bairro da Redenção, são os Sateré-Mawé”.

Os pesquisadores chegaram à aldeia Y'apyrehyt, ao lado de outra, Waikiru e logo o tuchaua Moisés Sateré nos recebeu. Apresentamo-nos, contamos o que queríamos fazer e aprender com eles. E a primeira coisa que o tuchaua mostrou foi uma cabana ao lado da sua, onde guardava objetos importantes, uma tese de mestrado sobre seu povo e... troféus de futebol! Os pesquisadores queriam aprender sobre cosmologia, rituais e se deparam com esses itens. Surpresos, perguntam-me se é assim que funciona a pesquisa. Sim, vamos em frente, se é isso que eles estão dizendo, não se pode deixar de lado, pois essa é a pista que estão dando. Aí de fato começou o nosso contato.

Os troféus eram do "Peladão", um grande torneio de futebol amador da cidade de Manaus, criada por um jornalista, reunindo diversas ligas, como a liga feminina, a liga de adultos, a liga de crianças e também a liga indígena. Neste último caso, todos os atletas devem comprovar sua origem étnica de indígenas. E como se prova? Apresentando a carteirinha da Funai. Mas muitos deles não a tinham, gerando motivos para muitas disputas, com acusações mútuas: se um time ganhava é porque tinha branco jogando e branco "jogava melhor que índio”. Mas às vezes era o contrário, o time de branco ganhava e falavam que era porque tinha índio, porque eles eram "mais fortes para jogar". Vários estereótipos eram acionados.

Significativo foi o episódio da mulher que, para poder entrar no time e disputar o torneio, teve de ir até aldeia onde a avó residia e construir sua árvore genealógica. Ela era indígena casada com um branco, outro complicador porque essa situação podia ser interpretada como se tivesse passado para o lado dos brancos. Ela lançou mão de sua posição no sistema de parentesco (tema caro à antropologia) mas para jogar futebol. Alude à discussão de Michael de Certeau, sobre táticas e estratégias. Se no campo da antropologia urbana geralmente esporte é tratado no campo do lazer, entretenimento, usos do tempo livre, aqui havia uma característica particular: discussão política de etnicidade - quem é indígena e quem não é - um lugar de disputas o tempo todo. Rodrigo Chiquetto (2014), um dos pesquisadores em campo, fez sua dissertação sobre o "peladão" mostrando como essa atividade, entre eles, representava uma das modalidades de estar e se apropriar da cidade.

Outra dissertação surgida dessa jornada manauara, que vai sair em livro, foi Seguindo Sementes, de Ana Luísa Sertã Mauro (2018), que começou a trabalhar 
com um tema muito comum, bastante conhecido dos etnólogos, o artesanato indígena. Ela entrou em contato com a AMISM, Associação das Mulheres Sateré-Mawé, e começou a frequentar a casa dessas mulheres enquanto faziam as peças. Lá ouvia as conversas que falavam sobre estética: "não, esse aqui é pro comércio da Itália, então tem um jeito certo de fazer”. Mas quando o colar é dirigido a São Paulo, é de outro estilo, inclusive influenciado pelas telenovelas. Quando é para eles próprios, os Sateré-Mawé usam-no de outra maneira, com sentido ritual. Após a feitura dos colares e pulseiras, Ana começou a ir junto com elas recolher as sementes pela cidade. Por isso o livro se chama Seguindo sementes, pois as mulheres tinham que recolher sementes e se algumas vinham da aldeia indígena de Ponta Alegre, na divisa com o Pará, baixo Amazonas, outras sementes eram colhidas na cidade de Manaus de árvores em terrenos baldios, no campus da UFAM, em um jardim particular, praças.

Elas conheciam a cidade de outra maneira, lendo-a através das sementes. Viviam andando para lá e para cá, de ônibus, a pé, sabendo onde encontrar seu material de trabalho. Dessa forma, começou uma discussão interessante porque parecia que, do ponto de vista meio do senso comum, nas ciências sociais, quando se fala de "índio urbano" vem a questão da periferia, da precariedade, da falta de serviço público e do "não é mais índio", a "aculturação" e "perda da identidade". Ao iniciar o trabalho na cidade com eles, através desse "de perto e de dentro", seguindo seus trajetos, nós percebemos como eles leem a cidade e a maneira como estabelecem alianças. As aldeias visitadas já foram "invasões", depois "ocupações" e foram as mulheres que começaram a ocupar esses espaços em Manaus.

Já José Agnello Alves Dias Andrade (2012) em sua pesquisa mostrou um circuito dos Sateré-Mawé mais amplo, em que não há a divisão cidade e aldeia. Por exemplo, Ponta Alegre, às margens do rio Andirá, baixo Amazonas, é uma das aldeias na terra indígena, de onde eles saem frequentemente para a cidade de Barreirinha onde o prefeito era Sateré-Mawé e aí têm suas casas; não aldeias urbanas como em Manaus, onde circulam o tempo todo e com regras dadas pelo parentesco e pela convivialidade. Parte daí a tese de doutorado de José Agnelo, mostrando como aquelas categorias, forjadas numa cidade como São Paulo, também podem ajudar a visualizar a dinâmica de comunidades como as dos Sateré-Mawé, cuja unidade de análise, neste caso, é o circuito, não a aldeia, ou a floresta, ou o rio. O mesmo pode ser aplicado a outros grupos, como os quilombolas, por exemplo, pois não é que vivem isolados e fechados nos quilombos. Circulam, tem seus trajetos regulares.

Utilizo esses exemplos para reforçar a ideia de que a construção de categorias etnográficas é suscitada pelo próprio campo. É claro que sempre se parte de um legado, de experimentos anteriores, mas na hora de operacionalizar as categorias, como no caso de Seguindo sementes, as questões vieram das interlocutoras, pois foram elas que descreveram à antropóloga como eram seus trajetos pela cidade e a convidaram para circular junto. Então, tem-se um mapa de Manaus das mulheres Sateré, por exemplo, que é diferente de outros, por exemplo, dos Tukano ou dos Ticuna.

Quero terminar esta aula voltando à pergunta colocada mais atrás: fazemos uma antropologia da cidade ou na cidade? Eunice Durham afirma que fazemos antropologia na cidade (DURHAM e TORRES, 2009): é o que ocorre ao delimitar os recortes dos surdos, das hortas urbanas, das torcidas organizadas de futebol, dos skatistas, dos indígenas na cidade e assim por diante. A outra perspectiva, antropologia da cidade, aplica-se mais a recortes dados pelas divisões admi- 
nistrativas, territoriais ou urbanísticas, como os bairros, os distritos. Contudo, trata-se de uma antinomia que pode ser resolvida como complementaridade.

O horizonte que se abre seria o seguinte: ao multiplicar pesquisas na cidade, fazendo os devidos links e conexões entre os diferentes recortes, caminha-se na direção de uma antropologia $d a$ cidade. Para um melhor entendimento e fundamentação dessa hipótese, faz-se necessário investigar a forma estrutural dos assentamentos humanos que, ao longo da história, podem ser classificados, de uma maneira ampla, entre acampamento, aldeia e cidade. Mas para isso seria necessário mobilizar uma série de conceitos em diálogo não só com a história, mas com a arqueologia e até com a paleontologia. Se o acampamento é associado, por exemplo, principalmente, com a forma de assentamento de caçadores e coletores, é possível encontrar sua ocorrência na periferia dos grandes centros urbanos com ocupações de terrenos por parte de movimentos sociais como o MST, por exemplo: que haveria de comum, então, entre essa prática e o modo de vida não apenas de povos caçadores e coletores atuais, mas daqueles nas longínquas eras do paleolítico? Esta é uma questão, contudo, que demandaria outra discussão e fica para um próximo encontro...

\section{Referências}

ANDRADE, José Agnello Alves Dias de. Indigenização da cidade: etnografia do circuito sateré-mawé em Manaus-AM e arredores. Dissertação (Mestrado em Antropologia Social) - Faculdade de Filosofia, Letras e Ciências Humanas, Universidade de São Paulo, São Paulo, 2012

AUGÉ, Marc. Não lugares: introdução a uma antropologia da sobremodernidade. Lisboa: 90 Graus, 2005 (1992).

BECKER, Howard. Art Worlds. Berkeley e Los Angeles: University of California Press, 1982.

CANDIDO, Antonio. Os parceiros do Rio Bonito: estudo sobre o caipira paulista e a transformação dos seus meios de vida. Rio de Janeiro: José Olympio, 1964.

CHIQUETTO, Rodrigo Valentim. A cidade do futebol. Etnografia sobre a prática futebolística na metrópole manauara. 2014. Dissertação (Mestrado em Antropologia Social) - Faculdade de Filosofia, Letras e Ciências Humanas, Universidade de São Paulo, São Paulo, 2014

DAMATTA, Roberto. A casa e a Rua. Espaço, Cidadania, Mulher e Morte no Brasil. Rio de Janeiro: Rocco, 1997.

DURHAM, Eunice Ribeiro; TORRES, Lilian de Lucca. Entrevista: Eunice Ribeiro Durham, Ponto Urbe [On line], 4, 2009.

EVANS-PRITCHARD, E. Os Nuer. São Paulo: Perspectiva, 1978 (1940).

FAVRET-SAADA, Jeanne. Ser afetado. Cadernos de Campo, 13: 155-161, 2005.

FOOTE WHYTE, William. Sociedade de Esquina. Rio de Janeiro: Jorge Zahar

Editor, 2005

HABERMAS, Jürgen. "Arquitetura moderna e pós-moderna”. In: ARANTES, Otília e ARANTES, Paulo E. (orgs.). Um ponto cego no projeto moderno de Jürgen Habermas. São Paulo: Brasiliense, 1992 (1981). 
HANNERZ, Ulf. "Os etnógrafos de Chicago". In: Explorando a cidade: em busca de uma antropologia urbana. Petrópolis: Vozes, 2015. pp. 28-68.

KANTOR, Íris; MACIEL, Débora; SIMÕES, Júlio (orgs.). A Escola Livre de Sociologia e Política; anos de formação 1933-1953. São Paulo: Escuta, 2001

LEACH, Edmund. A Diversidade da Antropologia. Lisboa: Edições 70, 1989 (1982).

LÉVI-STRAUSS, Claude. Tristes Trópicos. São Paulo: Companhia das Letras, 1996 (1955).

LOWRIE, Samuel H. Pesquisa de padrão de vida dos operários da limpeza pública da municipalidade de São Paulo. Revista do Arquivo Municipal, 51: 183310, 1938.

MACHADO, Giancarlo. A cidade dos picos: a prática do skate e os desafios da citadinidade. Tese (doutorado em Antropologia Social) - Faculdade de Filosofia, Letras e Ciências Humanas. Universidade de São Paulo, São Paulo, 2017.

MACHINI, Mariana Luíza Fiocco. Nas fissuras do concreto: política e movimento nas hortas comunitárias da cidade de São Paulo. Dissertação (Mestrado em Antropologia Social) - Faculdade de Filosofia, Letras e Ciências Humanas, Universidade de São Paulo, São Paulo, 2017.

MAGNANI, José Guilherme Cantor. Da Periferia ao Centro: Trajetórias de pesquisa em Antropologia Urbana. São Paulo: Terceiro Nome, 2012.

MAGNANI, José Guilherme Cantor. Festa no Pedaço: cultura popular e lazer na cidade. $2^{\mathrm{a}}$ Ed. São Paulo: Hucitec/Unesp, 1998 (1984).

MAGNANI, José Guilherme Cantor \& TORRES, Lilian de Lucca. Na Matrópole: textos de antropologia urbana. São Paulo: EDUSP, 1996

MALINOWSKI, Bronislaw. Os Argonautas do Pacífico Ocidental. São Paulo: Abril Cultural, 1978 (1922).

MARTINS, José de Souza. Viola quebrada. Debate \& Crítica, 4. Revista Quadrimestral de Ciências Sociais. São Paulo: Hucitec, 1974.

MAURO, Ana Luísa Sertã Almada. Seguindo sementes: circuitos e trajetos das mulheres Sateré-Mawé entre cidade e aldeia. São Paulo: Terceiro Nome/Gramma, 2018.

NORA, Pierre. Les lieus de mémoire. Paris: Editions Galimard, 1984

PARK, Robert Ezra. "A Cidade: sugestões para a investigação do comportamento humano no meio urbano". In: VELHO, Otávio (org.). O Fenômeno Urbano. Rio de Janeiro: Zahar ed., 1967. pp. 25-66.

STRATHERN, Marilyn. "O Efeito Etnográfico”. In: O Efeito Etnográfico e outros ensaios. São Paulo: Cosac Naify, 2014. pp. 345-507.

ZNANIECKI, Florian; THOMAS, William I. The Polish peasant in Europe and America: monograph of an immigrant group. Boston: The Gorhan Press, 1918.

WAGLEY, Charles. Amazon Town: a Study of Man in the Tropics. New York: Macmillan, 1953 